\title{
O emprego de linguagens aCessíveis para alunos com deficiência VISUAL em AULAS DE Ó PTICa
}

\author{
U SING ACCESSIBLE LANGUAGE WITH STUDENTS WITH VISUAL IM PAIRMENT WHEN \\ STUDYING OPTICS
}

\author{
Eder Pires de CAMARGO ${ }^{1}$ \\ Roberto NARDI ${ }^{2}$
}

RESU M 0: o presente artigo encontra-se inserido dentro de um estudo que busca compreender as principais alternativas para a inclusão de alunos com deficiência visual no contexto do ensino de física. Focalizando aulas de óptica, analisa as viabilidades comunicacionais entre licenciandos e discentes com deficiência visual. Para tal, enfatiza as estruturas empírica e semântico-sensorial das linguagens utilizadas, indicando fatores geradores de acessibilidade às informações veiculadas. Recomenda, ainda, alternativas que visam dar condições à participação efetiva do discente com deficiência visual no processo comunicativo, das quais se destacam: a identificação da estrutura semântico-sensorial dos significados veiculados, o conhecimento da história visual do aluno, a utilização de linguagens de estrutura empírica tátil-auditiva interdependente em contextos interativos, bem como, a exploração das potencialidades comunicacionais das linguagens constituídas de estruturas empíricas fundamental auditiva, e auditiva e visual independentes.

PALAVRAS-CHAVE: educação; educação especial; meios de ensino.

\begin{abstract}
A BSTRACT: This paper is part of a broader study aiming to understand the main alternatives for including students with visual impairments in the context of teaching physics. It analyzes the feasibility of communication between future physics teachers and their students with visual impairments during classes on optics. To this end, the study emphasizes empirical and semantic-sensorial structures of language that need to be used, indicating factors that enable access to information the teacher means to impart. Alternatives are recommended in order to enable students with visual impairments to participate as fully as possible in the communicative process. Among them we emphasize: the identification of semantic-sensorial structures; understanding the student's visual history; using interdependent empirical tactile-audio language structures in interactive contexts, as well as exploring communicational potentialities of languages made up of empirical structures that are primarily hearing or that have independent audio and visual structures.
\end{abstract}

KEYWORDS: education; special education; teaching techniques.

\footnotetext{
${ }_{1}^{1}$ Professor Dr. do Departamento de Física e Química da Faculdade de Engenharia da Universidade Estadual Paulista "Júlio de Mesquita Filho" e do programa de Pós-graduação em Educação para a Ciência (Área de Concentração: Ensino de Ciências) da Faculdade de Ciências da Universidade Estadual Paulista "Júlio de Mesquita Filho", Campus de Bauru, SP - camargoep@dfq.feis.unesp.br

2 Professor Dr. do departamento de educação e do programa de Pós-graduação em Educação para a Ciência (Área de Concentração: Ensino de Ciências) da Faculdade de Ciências da Universidade Estadual Paulista "Júlio de Mesquita Filho" - Bauru- SP - nardi@fc.unesp.br
} 


\section{IINTRODUÇÃo}

Nos dias atuais, o atendimento das diferentes necessidades educacionais dos al unos com e sem deficiências apresenta-se como o desafio mais importante que o professor deve enfrentar (RODRIGUES, 2003). A busca por uma didática inclusiva ${ }^{3}$ não é simples, deve superar os modelos pedagógicos tradicionais enfatizando o impacto de variáveis específicas na implantação de uma educação para todos. Como discutido nos Parâmetros Curriculares Nacionais (BRASIL, 1998), ao pensar a implementação da educação inclusiva há que se contemplar que saberes deve possuir o docente (CARVA LHO; GIL-PERES, 1994). Teoricamente, este professor deveria estar preparado para planejar e conduzir atividades de ensino que atendam às especificidades educacionais dos alunos com e sem deficiências, o que implica dizer que sua prática deve dar conta de atender as múltiplas formas de interação entre os participantes das atividades e os fenômenos estudados.

A inclusão posiciona-se de forma contrária aos movimentos de homogeneização e normal ização (SASSAKI, 1999). Defende o direito à diferença, a heterogeneidade e a diversidade (RODRIGUES, 2003). Efetiva-se por meio de três princípios gerais: a presença do aluno com deficiência na escola regular, a adequação da mencionada escola às necessidades de todos os seus participantes, e a adequação, mediante o fornecimento de condições, do al uno com deficiência ao contexto da sala de aula (SASSAKI, 1999). Implica uma relação bilateral de adequação entreambiente educacional eal uno com deficiência, em que o primeiro gera, mobiliza e direciona as condições para a participação efetiva do segundo (MITTLER, 2003). Na lógica da inclusão, as diferenças individuais são reconhecidas e aceitas e constituem a base para a construção de uma inovadora abordagem pedagógica. N essa nova abordagem, não há mais lugar para exclusões ou segregações, etodos os alunos, com esem deficiências, participam efetivamente (RODRIGUES, 2003). A participação efetiva é entendida em razão da constituição de uma dada atividade escolar que dá ao aluno com deficiência, plenas condi ções de atuação. A participação efetiva pode, portanto, servir como parâmetro sobre a ocorrência ou não de inclusão, além de explicitar as reais necessidades educacionais do aluno com deficiência.

Concluir que incluir alunos com deficiências em aulas de física, química, biologia, matemática, história, língua portuguesa, etc, deve ir além dos princípios gerais indicados, é reconhecer a necessidade do investimento em pesquisas que revelem propriedades ativas das variáveis específicas. Uma dessas variáveis refere-se à comunicação em aulas de física que contemplam a presença deal unos com deficiência visual, já que, a sala deaula podee deve ser considerada

\footnotetext{
${ }^{3}$ Define-se por didática inclusiva o conjunto de procedimentos educacionais intencionais adequado ao atendimento da diversidade humana. Em outras palavras, a didática inclusiva orienta-se por saberes organizativos e teórico-práticos cujo objetivo é favorecer a participação efetiva de todos os alunos, com e sem deficiência, em uma determinada atividade educacional.
} 
um ambiente de negociação/ compartilhamento de significados. Na seqüência, apresenta-se um posicionamento teórico sobre o fenômeno da comunicação.

A comunicação pode ser entendida como o processo social básico de produção e partilhamento do sentido através da materialização de formas simbólicas (FRAN ÇA, 2005). O termo "comunicação" exprime a relação entre consciências, isto é, refere-se ao processo de compartilhar um mesmo objeto de consciência (MARTINO, 2005). É objetivo dos participantes de um processo de comunicação, a busca de entendimento acerca de determinados significados presentes na subjetividade individual, o que implica dizer que esses participantes procuram uma unidade de compreensão de entidades não materiais existentes e inicialmente representadas na esfera da consciência, do psicológico, das idéias.

Para Mortimer e Scott (2002), se por um lado a comunicação é um mecanismo inerente à construção de significados na educação em ciências, por outro, o processo de aprendizagem pode ser compreendido como a negociação de novos significados num espaço comunicativo onde ocorre o encontro de diferentes idéias. Nessa perspectiva, o contexto de sala de aula pode ser caracterizado como local de práti cas comunicacionais específicas, isto é, específicas modalidades deexplicações e deraciocínios, usos diferentes dedados, deanal ogias, de leis e de princípios (COMPIANI, 2003).

Nos últimos vinte anos, a pesquisa sobre ensino de ciências vem crescendo no Brasil (MEGID NETO, 2000; NARDI, 2001). A inda quea quantidade de trabalhos acadêmicos na área de Ensino de ciências voltados para a questão dos alunos com deficiências seja muito inferior a de outras áreas, tem-se constatado também um discreto aumento nessas pesquisas (MORTIMER, 2007). Em linhas gerais, os estudos realizados sobre a temática do ensino de ciências no contexto dealunos com deficiências concentram-sena física ena deficiência visual, bem como, em situações educacionais que contemplaram somente a presença de alunos cegos e com baixa visão (CAMARGO 2000; 2005). Entretanto, grande parte das pesquisas sobre ensino de física/ deficiência visual não trataram explicitamente da inclusão do aluno cego e com baixa visão em aulas regulares (CAMARGO, 2005). Por isso, vêm-se realizando, desde 2005, uma investigação que visa compreender quais são as alternativas para a inclusão de alunos com deficiência visual em aulas defísica (alternativas para a participação efetiva desses alunos). A primeira etapa identificou alternativas e dificuldades encontradas por licenciandos para o desenvolvimento de planos de ensino para alunos com e sem deficiência visual (CAMARGO; NARDI, 2006). A segunda etapa tem por objetivo analisar a aplicação prática desses planos, ou seja, concentra a atenção no interior da sala deaula que contemplou a presença dealunos deficientes visuais e videntes.

O presente artigo indica resultados sobre a aplicação de quatro atividades de ensino de óptica no contexto educacional descrito. A nalisa a comunicação em sala de aula, explicitando e discutindo as linguagens adequadas à participação efetiva de alunos 
com deficiência visual. Enfatiza o fenômeno da inclusão escolar na perspectiva do ensino de óptica eda deficiência visual, reconhecendo a complexidade do referido fenômeno e a necessidade de recortes e estudos particularizados que enfoquem distintas deficiências e conteúdos escolares.

Optou-se por avaliar os conteúdos de ensino em função de seus aspectos conceituais e procedimentais, pois, a inclusão mostra-se eficaz e consolidada em termos de desenvolvimento dos conteúdos atitudinais (MANTOAN, 2003). Portanto, o foco para a verificação de condições de inclusão é concentrado nos aspectos conceituais e procedimentais dos conteúdos trabalhados pelo grupo de óptica. A abordagem desses conteúdos em sala de aula é fator central à inclusão ou exclusão dos alunos com deficiência visual em relação à construção de conhecimentos científicos. A idéia de conteúdo conceitual e procedimental aqui utilizada é aquela apresentada por Coll A pud Zabala (1998) que compreende os conteúdos de ensino em termos conceituais, procedimentais e atitudinais. Como explica Zabala (1998), os conteúdos conceituais estão relacionados ao conhecimento de fatos, conceitos e princípios; os procedimentais, às regras, técnicas e habilidades, e os atitudinais, a valores, atitudes e princípios éticos. Em outras palavras, conteúdos conceituais relacionam-se ao saber, os procedimentais, ao saber fazer, e os atitudinais, ao ser (ZABALA, 1998).

Como apontam os Parâmetros Curriculares Nacionais, a inclusão escolar impõe-se como uma perspectiva a ser pesquisada e experimentada na realidade brasileira (BRASIL, 1998). Dessa forma, em relação ao ensino de Física aos alunos com deficiência visual, é de fundamental importância a execução de pesquisas que visem contribuir com a formação do professor, haja vista que os alunos com deficiência visual começaram a freqüentar espaços sociais como os da escola, do trabalho, etc, que sempre foram deles, e que, por questões relacionadas a paradigmas de normalização de comportamentos, foram-lhes retirados.

\section{MÉTODO}

\subsection{CONTEXTO DAS AULAS DE ÓPTICA}

As quatro atividades (que totalizaram 16 horas) do grupo de óptica ocorreram no Colégio Técnico Industrial Prof. Isaac Portal Roldán (CTI - Bauru). Essas atividades fizeram parte de um curso de extensão de 80 horas denominado "O Outro Lado da Física", oferecido pelo curso de Licenciatura em física da UNESP de Bauru durante o segundo semestre de 2005. Além de óptica, esse curso também contemplou aulas de eletromagnetismo, mecânica, termologia e física moderna. O grupo de óptica era constituído por seis licenciandos que se alternaram entre as funções de coordenação e apoio das atividades. Acerca da preparação para a aplicação dos módulos de ensino, cabem os seguintes comentários. 
Os licenciandos definiram que as atividades constituiriam um curso de extensão a ser oferecido pela UNESP para uma determinada escola da rede regular de ensino de Bauru. A escolha do CTI deu-se por quatro fatores: (a) O CTI é um colégio vinculado à UNESP; (b) Existência de boas relações entre a mencionada instituição e a UNESP de Bauru; (c) cursos semelhantes já haviam sido aplicados com sucesso no CTI; (d) proximidade entre o CTI ea UNESP. Tal proximidade facilitou o deslocamento dos licenciandos.

No início do segundo semestre de 2005, os licenciandos iniciaram um período de divulgação junto aos al unos da mencionada instituição. O CTI oferece cursos técnicos de mecânica, el etrônica e processamento de dados, bem como, o ensino médio propedêutico. Estudam no $\mathrm{CTI}$ alunos da cidade e da região de Bauru com idade média de 15 anos. O número de vagas para a participação dos alunos do CTI no curso "O outro lado da Física" foi de trinta e cinco, sendo que o número de inscritos foi de aproximadamente setenta alunos. A escolha dos trinta e cinco participantes deu-se por sorteio. Dessa forma, os alunos oriundos do CTI e participantes do curso eram provenientes dos três anos do ensino médio (profissionalizante e propedêutico).

Paralelamente ao processo de divulgação descrito, entrou-se em contato com a Escola Estadual Mercedes P. Bueno, localizada na cidade de Bauru - SP, a fim de convidar al unos com deficiência visual para participarem do curso anteriormente mencionado. A escola Mercedes foi procurada, pois, no CTI, não havia alunos com deficiência visual matriculados. A escola Mercedes P. Bueno possui uma sala de recursos pedagógicos que procura atender às necessidades educacionais de alunos com deficiência visual (Ex. ensino do Braille, transcrição de textos ou provas em Braille). Dois alunos com deficiência visual interessaramse em participar do curso "O outro lado da Física". Esses alunos na ocasião possuíam as seguintes características em relação à deficiência visual e à escolaridade: ambos eram cegos; um possuía 15 anos de idade e cursava a 8a série do ensino fundamental (atual nona série), e o outro possuía 34 anos ecursava a oitava série do ensino de jovens e adultos. O aluno de 15 anos de idade era cego de nascimento e o de 34 perdera a visão aos vinte e quatro anos. O aluno cego de nascimento participou de todas as aulas, e o que perdeu a visão ao longo da vida, da terceira equarta aulas. Para fins desi gilo, o al uno cego de nascimento será identificado neste texto como aluno (B), e o que perdeu a visão ao longo da vida, como aluno $(A)$.

\subsection{Registro e ANÁlise de dados}

Todas as atividades foram filmadas e transcritas na íntegra. Constituiu-se, dessa forma, o corpus de análise (BARDIN, 1977). Em seguida, obedecendo aos critérios de análise temática: exploração do material; tratamento dos resultados e interpretação (BARDIN, 1977), foram identificadas linguagens 
avaliadas como viabilidade comunicacional entre os videntes e os deficientes visuais. Essa avaliação foi conduzida pela idéia de acessi bilidade dos alunos com deficiência visual às informações veiculadas em sala de aula. A acessibilidade, por sua vez, levou em conta as características da linguagem mediante a história visual do discente, ou seja, se ele nasceu cego ou se perdeu a visão ao longo da vida.

No processo de exploração do material, realizou-se a fragmentação do corpus de análise (BARDIN, 1977). Durante a fragmentação, foram selecionados trechos que continham falas dos participantes caracterizadas pelo mesmo conteúdo conceitual ou procedimental e pelas mesmas estruturas empírica e semântico-sensorial (mesma linguagem). Em outras palavras, a fragmentação foi orientada pela identificação de um determinado perfil comunicacional utilizado na veiculação de conteúdos de óptica. A pós a fragmentação e a seleção, realizou-se o agrupamento de viabilidades semel hantes do ponto de vista lingüístico. Como decorrência, foram identificadas viabilidades comunicacionais ${ }^{4}$ inerentes aos discentes com defi ciência visual. Essas viabilidades serão abordadas na análise dos dados.

\subsection{Categ oria de ANÁlise dos dados}

Visa caracterizar e explicitar quais linguagens empregadas pelos licenciandos nas atividades de óptica tornaram acessíveis aos alunos com deficiência visual as informações veiculadas. A acessibilidade será avaliada em razão das estruturas empírica esemântico-sensorial da linguagem em comparação com a característica visual dos discentes. Na seqüência, descrevem-se as mencionadas estruturas.

\subsection{Estrutura Empírica da Linguagem}

Refere-se ao suporte material da linguagem (MARTINO, 2005), isto é, à forma por meio da qual uma determinada informação é materializada, armazenada, veiculada e percebida. Pode se organizar em termos fundamentais e mistos. As estruturas fundamentais são constituídas pelos códigos visual, auditivo etátil, articulados de forma autônoma e/ ou independenteuns dos outros. As estruturas mistas surgem quando os códigos fundamentais se combinam de forma interdependente, ou seja, estruturas áudio-visual, tátil-visual, tátil-auditiva etátil-visual-auditiva. Observa-se que os sentidos de natureza olfativa e gustativa não serão, para efeitos de análise dessa categoria, considerados como códigos sensoriais utilizados para veiculação de informações. Embora a existência de

\footnotetext{
${ }_{4}$ Define-se por viabilidade comunicacional a veiculação de informação acessível aos alunos com deficiência visual. Em outras palavras, o termo viabilidade comunicacional pode ser entendido como os processos material e subjetivo adequados de transmissão (pelo vidente) e recepção (pelo deficiente visual) de significados (neste caso de significados ópticos).
} 
tais códigos seja possível, entende-se, por hipótese, que, para contextos de sala de aula de óptica, ela seja desprezível. Na seqüência, são definidas as estruturas empíricas que representaram viabilidade comunicacional.

1) Tátil-auditiva interdependente: caracteriza-se pela dependência mútua entre os códigos tátil e auditivo que dão suporte material à veiculação de informações. Do ponto de vista empírico, o acesso às linguagens com essa característica somente pode se dar por meio da observação simultânea dos códigos mencionados, pois a observação parcial deum dos códigos não desfaz a interdependência de seu suporte material.

2) Fundamental auditiva: caracteriza-se por possuir apenas códigos sonoros. $O$ acesso às linguagens com essa estrutura empírica dá-sepor meio da observação auditiva dos mencionados códigos (único suporte material).

3) Auditiva e visual independentes: caracteriza-se pela independência entre os códigos auditivo e visual que Ihe servem de suporte material. Ocorre, por exemplo, quando se projetam e falam-se as mesmas informações. Por isso, o nível do detal hamento oral determina padrões de qual idade deacessibilidade às informações veiculadas.

4) Tátil e auditiva independentes: difere da estrutura 1. Caracteriza-se pela independência entre os códigos tátil e auditivo que Ihe servem de suporte material. Foi identificada em ocasiões em queo discentecom deficiência visual reconheceu equipamentos experimentais por meio do tato e da audição. Dessa forma, cada tipo de percepção mencionada apresentava determinada característica do equipamento (auditiva ou tátil).

\subsubsection{Estrutura Semântico-sensorial da Linguagem}

Refere-se aos efeitos produzidos pelas percepções sensoriais no significado de fenômenos, conceitos, objetos, situações e contextos (DIMBLERY; BURTON, 1990). Esses efeitos são entendidos, por meio de dois referenciais relacionais entre significado e percepção sensorial: a indissociabilidade e a vinculação. Significados indissociáveis são aqueles cuja representação 5 mental é dependente de determinada percepção sensorial. Esses significados nunca poderão ser representados internamente por meio de percepções sensoriais distintas da que os constituem. Significados vinculados são aqueles cuja

\footnotetext{
${ }^{5}$ A idéia de representação aqui utilizada é aquela contida em Eisenck e Keane (1991). Segundo os autores (op. Cit. p. 202) representação é “Qualquer notação, signo ou conjunto de símbolos capaz de representar, mesmo na ausência do representado, Algum aspecto do mundo externo ou de nossa imaginação". De forma mais específica, a presente categoria fundamenta-se no conceito de "representações internas" ou "representações mentais", que ocorrem no nível subjetivo da cognição, do pensamento. Em outras palavras, tais representações referem-se "às formas em que codificamos características, propriedades, imagens, sensações, etc, de um objeto percebido ou imaginado, bem como, de um conceito abstrato" (EISENCK; KEANE, 1991, p. 202). Na seqüência, são definidas as estruturas semântico-sensoriais que representaram viabilidade comunicacional.
} 
representação mental não é exclusivamente dependente da percepção sensorial utilizada para seu registro ou esquematização. Sempre poderão ser representados por meio de percepções sensoriais distintas da inicial. Há, portanto, para o caso da indissociabilidade, uma relação indissolúvel entre significado e percepção sensorial, enquanto que para o caso da vinculação, não.

1) Significados vinculados às representações não-visuais: possuem as seguintes características: (a) são significados registrados por códigos não-visuais, e observados pelo tato, audição, etc. (b) tornam-se, por este motivo, representados internamente por imagens mentais não-visuais (PAIVIO apud BAJO; CAÑA, 1991); (c) sempre poderão ser registrados e internamente representados por meio de códigos e representações diferentes das que os constituem. Para as atividades do grupo de óptica, esses significados são os seguintes: registros táteis de raios de luz paral elo, convergente e divergente, das características geométricas das reflexões regular e difusa e do fenômeno da dispersão da luz, registro tátil da geometria da relação objeto, imagem e raio de luz em lentes e espel hos planos e esféricos, registro tátil de ângulos de incidência, reflexão e refração, relação entre cor e comprimento de onda, diferença entre a velocidade da luz na água e no ar, etc...

2) Significados indissociáveis de representações não-visuais: somente podem ser registrados e internamente representados por meio de códigos e representações não-visuais. A bsorção da luz, relação entre energia luminosa e térmica, etc, são exemplos de tais significados. O acesso e/ ou compreensão de fenômenos que contêm esses significados é dependente da observação não-visual (tátil), na medida em que não são possíveis o registro externo e a representação interna dos mesmos por meio de códigos e imagens visuais.

3) Significados indissociáveis de representações visuais: somente podem ser registrados e internamente representados por meio de códigos e representações visuais. Característica visual da cor, idéia visual de transparente, opaco e translúcido, característica visual dos fenômenos: reflexão e refração da luz, idéia visual de imagem e de fonte deluz, concepção de visão, são exemplos de tais significados.

A teoria de Vigotski sobre a cegueira justifica que os significados indissociáveis de representações visuais são inacessíveis às pessoas cegas de nascimento. Essa teoria afirma que tais pessoas não compreendem o fenômeno luminoso em seu âmbito visual, esim a partir dos significados não visuais esociais a tal fenômeno relacionados (VIGOTSKI, 1997). N esse sentido, a cegueira nativa em nada se assemelha à sensação visual de um vidente com os olhos vendados, ou seja, o cego de nascimento não vive envolvido na escuridão, já que as idéias de claro, escuro, cores, etc, não possuem, para este indivíduo, um significado visual. 


\section{RESULTADOS: ANÁLISE DAS LINGUAGENS GERADORAS DE VIABILIDADE COMUNICACIONAL}

Foram identificadas, para o aluno (B), cinco linguagens geradoras de viabilidade de comunicação, e para o al uno $(A)$, três linguagens. As linguagens inerentes ao aluno (B) organizaram-se em razão de duas estruturas semânticosensoriais equatro estruturas empíricas. São elas: Estruturas semântico-sensoriais: significado vinculado às representações não-visuais e significado indissociável de representações não-visuais; Estruturas empíricas: tátil-auditiva interdependente, fundamental auditiva, auditiva e visual independentes e tátil e auditiva independentes. Já as linguagens inerentes ao al uno $(A)$ organizaram-se em razão de duas estruturas semântico-sensoriais e duas estruturas empíricas. São el as: estruturas semântico-sensoriais: significado vinculado às representações não-visuais e significado indissociável de representações visuais; estruturas empíricas: tátil-auditiva interdependente e fundamental auditiva.

Note-se que as estruturas empíricas, auditiva e visual independentes, e tátil e auditiva independentes, bem como, a estrutura semântico-sensorial, com significado indissociável de representações não-visuais, somente constituíram linguagens geradoras de viabilidades ao aluno (B). Isso se deve ao fato do mencionado aluno ter participado de todas as atividades e, conseqüentemente, demomentos em quetais estruturas foram empregadas. Por outro lado, a estrutura semântico-sensorial, com significado indissociável de representações visuais, constituiu linguagens acessíveis apenas ao al uno (A). Isso se deve ao fato de esse aluno ter enxergado por 24 anos e, portanto, ter construído representações visuais de fenômenos ópticos.

O Quadro 1 explicita as estruturas empíricas e semântico-sensoriais das linguagens geradoras de viabilidades comunicacionais ao aluno (B), suas relações e respectivas quantidades.

\begin{tabular}{|l|l|l|l|l|l|}
\hline $\begin{array}{l}\text { Empírica (direita) } \\
\text { Semântico-sensorial } \\
\text { (abaixo }\end{array}$ & $\begin{array}{l}\text { Tátil-auditiva } \\
\text { interdependente }\end{array}$ & $\begin{array}{l}\text { Fundamental } \\
\text { auditiva }\end{array}$ & $\begin{array}{l}\text { Auditiva e visual } \\
\text { independentes }\end{array}$ & $\begin{array}{l}\text { Tátil e auditiva } \\
\text { independentes }\end{array}$ & $\begin{array}{l}\text { Total } \\
\text { horizontal/porcentagem }\end{array}$ \\
\hline $\begin{array}{l}\text { Significado vinculado às } \\
\text { representações não- } \\
\text { visuais }\end{array}$ & $59 / 60,82 \%$ & $30 / 30,93 \%$ & $4 / 4,12 \%$ & 0 & $93 / 95,88 \%$ \\
\hline $\begin{array}{l}\text { Significado de } \\
\text { indissociável não- } \\
\text { representações } \\
\text { visuais }\end{array}$ & 0 & $2 / 2,06 \%$ & 0 & $2 / 2,06 \%$ & $4 / 4,12 \%$ \\
\hline $\begin{array}{l}\text { Total } \\
\text { vertical/porcentagem }\end{array}$ & $59 / 60,82 \%$ & $32 / 33 \%$ & $4 / 4,12 \%$ & $2 / 2,06 \%$ & Total 97/100\% \\
\hline
\end{tabular}

Quadro 1 - viabilidade de comunicação - aluno (B): estruturas empírica e semântico-sensorial das linguagens. 
O Quadro 2 explicita as estruturas empíricas e semântico-sensoriais das linguagens geradoras de viabilidades comunicacionais ao aluno $(A)$, suas relações e respectivas quantidades.

\begin{tabular}{|c|c|c|c|}
\hline $\begin{array}{c}\text { Empírica (direita) } \\
\text { Semântico-sensorial (abaixo) }\end{array}$ & $\begin{array}{c}\text { Tátil- } \\
\text { auditiva } \\
\text { interdepen- } \\
\text { dente }\end{array}$ & $\begin{array}{c}\text { Fundamental } \\
\text { auditiva }\end{array}$ & $\begin{array}{c}\text { Total } \\
\text { horizontal/porcen- } \\
\text { tagem }\end{array}$ \\
\hline $\begin{array}{c}\text { significado vinculado às } \\
\text { representações não-visuais }\end{array}$ & $33 / 76,74 \%$ & $5 / 11,63 \%$ & $38 / 88,37 \%$ \\
\hline $\begin{array}{c}\text { significado indissociável de } \\
\text { representações visuais }\end{array}$ & 0 & $5 / 11,63 \%$ & $5 / 11,63 \%$ \\
\hline Total vertical/porcentagem & $33 / 76,74 \%$ & $10 / 23,26 \%$ & Total 43/100\% \\
\hline
\end{tabular}

Quadro 2 - viabilidade de comunicação - aluno (A): estruturas empírica e semântico-sensorial da linguagem.

Tomando por base os dados dos Quadros 1 e 2, apresentam-se na seqüência as cinco linguagens geradoras de viabilidade comunicacional ao aluno (B), e as três, ao aluno (A). É importante destacar que existem duas linguagens comuns aos alunos. Por esse motivo, o número total de linguagens explicitadas será de seis e não de oito. Essas linguagens encontram-se definidas pela relação: estrutura empírica/ estrutura semântico-sensorial. Observa-se que para exemplificar uma determinada linguagem, foram transcritos trechos oriundos das atividades do grupo de óptica. Esclarece-se que as siglas (L), (A) e (B) representam, respectivamente, declarações dos licenciandos, do aluno que perdeu a visão ao longo da vida e do aluno cego de nascimento.

Linguagem 1 - Tátil-auditiva interdependente/significado vinculado às representações não-visuais: em relação à presente linguagem, o recurso instrucional empregado para apoiar o processo comunicativo possuía registros táteis percebidos pelos alunos com deficiência visual e descritos oralmente pelos licenciandos. Esse perfil lingüístico foi responsável por $60,82 \%$ das viabilidades comunicacionais inerentes ao aluno (B) e 76,74\%, ao aluno (A). Um exemplo dessa linguagem é apresentado na seqüência.

L: Esses daqui são os raios divergentes, el es vêm daqui nesse sentido, ou seja, eles vão abrindo, conseguem perceber isto?

L: E os do lado são os convergentes, el es vêm daqui, eles vão fechando, está perceben do? L: Então, quando a gente estiver trabalhando com raio de luz, a gente vai estar trabal hando com um risquinho só, só com este risquinho aqui.

M ostra as representações táteis da maquete de raio de luz (foto 1). 


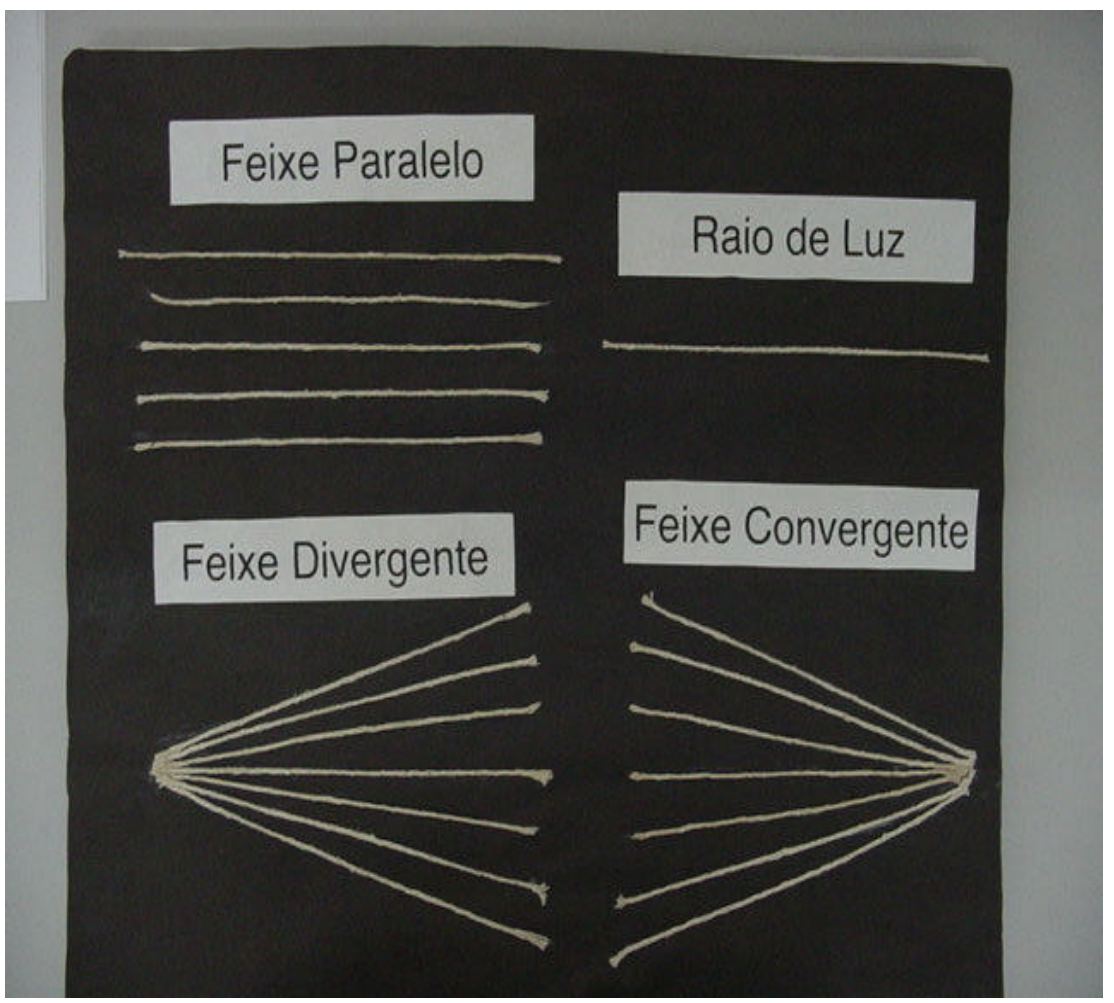

Foto 1- Registro tátil-visual de raio de luz, raios paralelos, convergentes e divergentes.

O que marca essa linguagem é a ação do licenciando conduzir a mão do aluno com deficiência visual sobre os registros táteis contidos nas maquetes ou materiais. Enquanto conduz, descreve auditivamente aquilo que se encontra registrado tatilmente.

Linguagem 2 - Fundamental auditiva/significado vinculado às representações não-visuais: aqui cabe destacar que os licenciandos falavam acerca de registros não-visuais ou idéias conhecidas dos alunos com deficiência visual. Essa linguagem foi responsável por 30,93\% das viabilidades de comunicação inerentes ao aluno (B), e 11,63\%, ao aluno (A). Na seqüência, é apresentada a transcrição de um trecho caracterizado por essa linguagem.

$L: 0$ que seria essa idéia de comprimento de onda?

L: Imaginem uma corda balançando para cima e para baixo; ela tem 
aquela parte que sobe e desce e que sobe de novo.

L: Então a gente chama de crista a cada subida da corda; entre duas cristas você tem o que a gente chama de comprimento de onda.

$\mathrm{L}$ : I maginem as ondas do mar. V em uma onda, aí sabe quando tem aquela seqüência? I magina que entre uma e outra você tem duas cristas, é como se fosse isso o comprimento de onda.

L: 0 vermelho tem o comprimento de onda maior, então, a distância do vermelho entre uma crista e outra é maior do que a do azul que tem o comprimento de onda menor.

O que marca esse perfil lingüístico é o detalhamento oral de significados vinculados às representações não-visuais. No exemplo apresentado, o licenciando descreveu comprimento de onda a partir do movimento da corda e das ondas do mar e relacionou a idéia mencionada às cores. Esses fenômenos, quecontêm significados vinculados às representações não-visuais, foram acessíveis aos alunos (A) e (B).

Linguagem 3 - Tátil-auditiva interdependente/significado indissociável de representações visuais: foi identificada em $11,63 \%$ das viabilidades comunicacionais inerentes ao aluno (A). A presente linguagem foi acessível ao mencionado aluno, pois o mesmo enxergou por 24 anos e, portanto, demonstrou ter compreendido os significados indissociáveis de representações visuais. Para o aluno (B), essa linguagem foi inacessível, já que esse aluno nasceu cego e não tem acesso aos significados com a característica semântico-sensorial aqui mencionada. $\mathrm{Na}$ seqüência, apresentam-se algumas declarações que representam a linguagem discutida.

L: A qui onde está sua mão é transparente; então a luz passa, e daqui para cá ele é branco.

L: V ocêse lembra do ol ho quetinha uma parte branca, depois uma parte colorida eum furinho no meio?

A: Lembro.

L: Então, essa daqui é a parte branca, não passa luz através dela; aqui seria a parte colorida, e, dentro dessa parte colorida aqui, tem a parte da íris do olho.

A: Onde tem a cor.

L: Essa é a pupila, e essa abertura aí abre ou fecha dependendo do tanto de luz.

A : É a pupila, não é?

L: V amos de novo, a íris é a parte colorida; esse furinho, quando está muito claro, fica pequenininho e, quando está escuro, fica grandão.

O trecho transcrito relata a abordagem dos significados indissociáveis de representações visuais. Para tal, o licenciando utilizou uma maquete desmontável do ol ho humano. (Alguns exemplos dos significados abordados são os seguintes: características visuais e função dos el ementos oculares). Como (A) 
enxergou por 24 anos, tais significados foram compreendidos por ele, pois, durante o tempo em que foi vidente, teve a oportunidade de construir representações visuais de significados indissociáveis dessas representações.

\section{Linguagem 4 - Auditiva e visual independentes/significado} vinculado às representações não-visuais: esse perfil lingüístico representou $4,12 \%$ das viabilidades comunicacionais inerentes ao aluno (B). Na seqüência, apresentam-se exemplos de frases com o perfil lingüístico abordado.

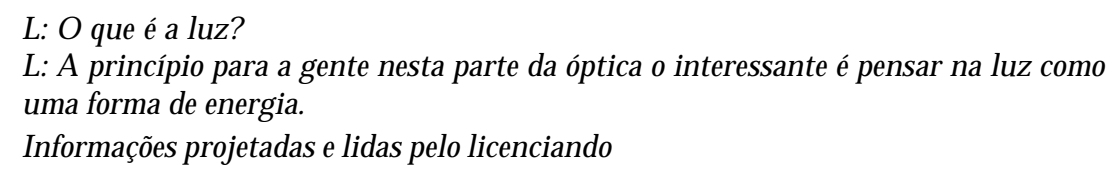

Uma característica marcante da presente linguagem é a simultaneidade entre projeção e descrição oral de informações. Tais informações contêm os mesmos significados vinculados às representações não-visuais.

Sobre o trecho transcrito, cabe a seguinte análise: a intenção do licenciando foi a de apresentar aos discentes o significado de luz. Para tanto, vinculou a idéia de algo relacionado à visão (luz) à de algo mais abstrato, não relacionado diretamente à percepção visual (energia). Nesse contexto, se o significado de (B) para a idéia de luz não é influenciado pela percepção visual, o significado de energia também não é, pois energia éal go abstrato e não depende de representações visuais para ser compreendido.

\section{Linguagem 5 - Fundamental auditiva/significado indissociável de} representações não-visuais: essa linguagem representou 2,06\% das viabilidades comunicacionais inerentes ao al uno (B). Na seqüência, é apresentado um trecho que contém a presente característica lingüística.

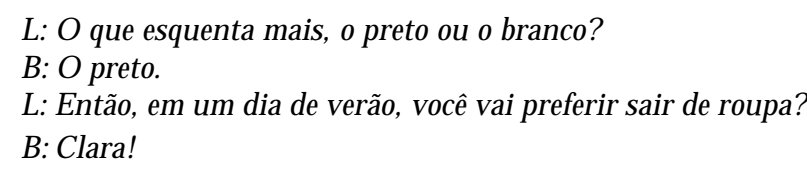

O trecho iniciou-se com a questão: o que esquenta mais, o branco ou o preto? Nesse contexto, respondeu o aluno (B) que seria mais adequado, no verão, o uso de roupas de cor clara. Para explicar a relação entre as cores e a sensação térmica, o licenciando recordou um experimento realizado anteriormente. N esseexperimento, incidiram luzes de diferentes freqüências sobre as camisas dos alunos para que as cores refletidas fossem observadas. Iniciou-se, naquele momento, uma série de perguntas do licenciando e respostas dos alunos videntes sobre a cor de uma camisa branca quando sobre ela incidia ora luz vermelha, ora luz azul. O licenciando utilizou as descrições dos alunos videntes para argumentar que o preto absorve todas as cores, e o branco reflete todas as 
cores. Por fim, o licenciando explicou que roupas brancas aquecem menos pelo fato de absorverem em menor quantidade a energia luminosa que roupas pretas. Durante sua argumentação, o licenciando não realizou novamente experimentos que envolvessem absorção da luz.

Do ponto de vista semântico-sensorial, considera-se que o licenciando não relacionou de forma exclusiva o significado de cor a representações visuais. Se, por um lado, o experimento, anteriormente realizado, veiculou informações visuais, por outro, o exemplo das roupas e da sensação térmica possibilitou um referencial não-visual para a compreensão de cor. N esse contexto, é possível que $\mathrm{B}$, ao associar o branco e o preto a distintas sensações térmicas, tenha estabelecido representações não-visuais para a idéia de cor e, dessa forma, compreendido a informação veiculada pelo licenciando.

\section{Linguagem 6 - Tátil e auditiva independentes/significado} indissociável de representações não-visuais: a presente linguagem foi responsável por 2,06\% das viabilidades comunicacionais inerentes ao aluno (B). Foi identificada quando (B) reconheceu de forma tátil e auditiva o formato e o som de um cal eidoscópio (reconhecimento não-visual de material experimental).

O Quadro 3 explicita sinteticamente as linguagens geradoras de viabilidades comunicacionais, a característica peculiar da linguagem, suas quantidades e porcentagens, bem como, o recurso instrucional mais freqüente em cada uma delas.

\begin{tabular}{|c|c|c|c|c|}
\hline Linguagem & $\begin{array}{l}\text { Quantidade/porcen- } \\
\text { tagem (A) }\end{array}$ & $\begin{array}{l}\text { Quantidade/porcen- } \\
\text { tagem (B) }\end{array}$ & $\begin{array}{l}\text { Característica } \\
\text { peculiar }\end{array}$ & $\begin{array}{l}\text { Recurso } \\
\text { instrucional } \\
\text { mais empregado }\end{array}$ \\
\hline $\begin{array}{l}\text { Tátil-auditiva } \\
\text { interdependente/significado vinculado } \\
\text { às representações não-visuais }\end{array}$ & $33 / 76,74 \%$ & $59 / 60,82 \%$ & $\begin{array}{l}\text { Condução das } \\
\text { mãos do aluno }\end{array}$ & Maquetes táteis \\
\hline $\begin{array}{lr}\text { Fundamental } & \text { auditiva/significado } \\
\text { vinculado às representações não-visuais }\end{array}$ & $5 / 11,63 \%$ & $30 / 30,93 \%$ & $\begin{array}{l}\text { Recorrência à } \\
\text { "imagens não- } \\
\text { visuais mentais" }\end{array}$ & Não utilizado \\
\hline $\begin{array}{l}\text { Tátil-auditiva } \\
\text { interdependente/significado } \\
\text { indissociável de representacões visuais }\end{array}$ & $5 / 11,63 \%$ & 0 & $\begin{array}{l}\text { Recorrência a } \\
\text { "imagens visuais } \\
\text { mentais" }\end{array}$ & Maquetes táteis \\
\hline $\begin{array}{lrr}\text { Auditiva } & \mathrm{e} & \text { visual } \\
\text { independentes/significado vinculado às } \\
\text { representações não-visuais }\end{array}$ & 0 & $4 / 4,12 \%$ & $\begin{array}{l}\text { Indicar } \\
\text { oralmente frases } \\
\text { projetadas }\end{array}$ & $\begin{array}{l}\text { Data-show, } \\
\text { retroprojetor }\end{array}$ \\
\hline 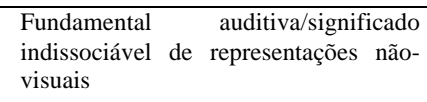 & 0 & $2 / 2,06 \%$ & $\begin{array}{l}\text { Descrição oral de } \\
\text { significados não- } \\
\text { visuais }\end{array}$ & Não utilizado \\
\hline $\begin{array}{l}\text { Tátil } \quad \text { e } \\
\text { independentes/significado indissociável } \\
\text { de representações não-visuais }\end{array}$ & 0 & $2 / 2,06 \%$ & $\begin{array}{l}\text { Descrição tátil e } \\
\text { auditiva }\end{array}$ & $\begin{array}{l}\text { Equipamentos } \\
\text { experimentais }\end{array}$ \\
\hline Total de viabilidades (vertical) & 43 & 97 & $\mathrm{X}$ & $\mathrm{X}$ \\
\hline
\end{tabular}

Quadro 3 - Síntese e características das linguagens geradoras de viabilidades comunicacionais. 


\section{ReComendações PARA PARTICIPAÇão do ALUNo COM DEFICIÊNCIA VISUAL EM AULAS de ÓTICA}

Na seqüência, serão apresentadas sete recomendações à participação efetiva (de inclusão) do aluno com deficiência visual em aulas de óptica. Fundamentar-se-ão nas condições de acessibilidade do discente, isto é, a consideração de sua potencialidade sensorial mediante as linguagens geradoras de viabilidade comunicacional. Nesse sentido, as recomendações buscarão contemplar a deficiência visual como um todo, ou seja, al unos cegos de nascimento, al unos que perderam a vista ao longo da vida, e alunos com baixa visão (acuidade visual menor que 20/200). Observa-se que legalmente, é considerada pessoa com deficiência visual aquela que apresenta uma acuidade visual menor que 20/200 à percepção de luz, ou seja, após a correção da visão de seu melhor olho, ela vê a menos de 20 metros o que uma pessoa de visão comum pode enxergar a 200 metros - DECRETO NO. 3.298/ 1999 - (BRASIL, 2004).

1) Conhecimento da história visual do aluno: o aluno é cego de nascimento? Perdeu a visão ao longo da vida? Quanto tempo enxergou? Possui resíduo visual? Esse resíduo pode ser utilizado em sala de aula? Em que medida pode ser utilizado? Exemplos: (a) se o aluno não nasceu cego ou possui baixa visão, os significados indissociáveis de representações visuais Ihes são potencialmente comunicáveis. (b) dependendo do resíduo visual do aluno, registros visuais ampliados podem ser utilizados nos processos de comunicação; (c) dependendo do resíduo visual do aluno, ele pode observar visualmenteal guns fenômenos ópticos como o entortamento aparente do lápis em um copo com água ou registros visuais provenientes de simulações computacionais, vídeos, esquemas projetados ou desenhados.

2) Identificação da estrutura semântico-sensorial dos significados ópticos vei culados: essa identificação éfundamental , pois significados vinculados às representações visuais sempre poderão ser registrados e vinculados a outro tipo de percepção (tátil, auditiva, etc). Esse foi o procedimento adotado pelos licenciandos, já quea grande maioria dos significados veiculados pelas linguagens geradoras de viabilidades foram vinculados a representações não-visuais. Destaca-se que significados vinculados às representações visuais possuem as seguintes características: (a) são significados registrados por códigos visuais e observados pelo olho; (b) tornam-se, por este motivo, representados internamente por imagens mentais; (c) sempre poderão ser registrados e internamente representados por meio de códigos e representações não-visuais. 
3) Construir de forma sobreposta registros táteis e visuais de comportamentos ópticos de significados vinculados às representações visuais (vincular os significados às representações não-visuais): é necessária a construção de maquetes que descrevam tátil e visualmente comportamentos ópticos como desvio sofrido pela luz no fenômeno da refração, comportamento dos raios incidentes e refletidos, nos fenômenos da reflexão regular e difusa, comportamento dos raios incidentes e refletidos, em espelhos planos, esféricos e em lentes, etc. Na seqüência, apresenta-se o exemplo de um material de interface tátil e visual construído para o ensino do fenômeno de refração da luz (foto 2).

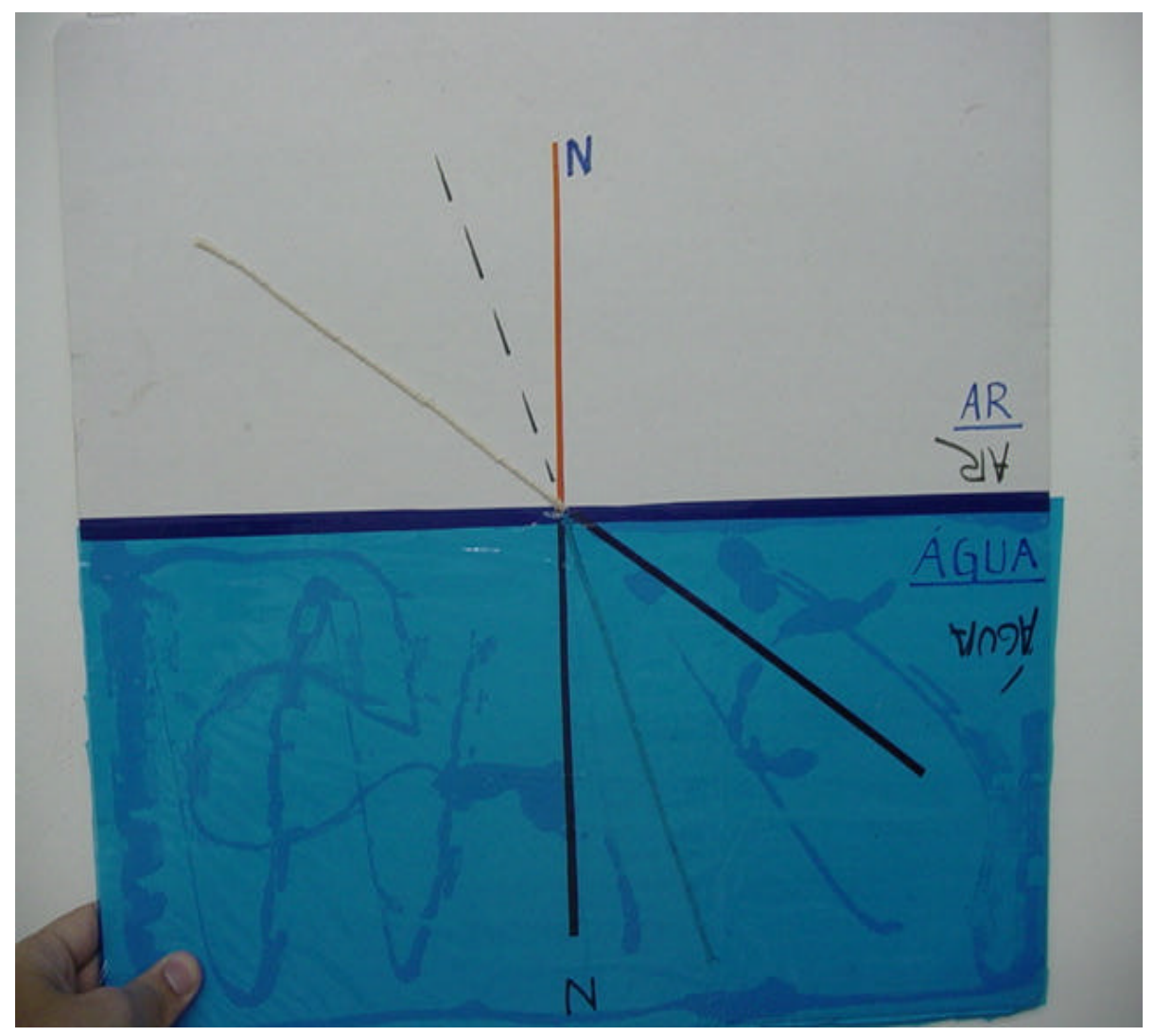

Foto 2 - registro tátil-visual do fenômeno da refração da luz.

O registro tátil e visual simultâneo de fenômenos como o explicitado na foto 2 torna-os acessíveis a alunos cegos e com baixa visão, além de criar canais de comunicação entre esses alunos, seus colegas videntes e o docente. 
4) Exploração das potencialidades comunicacionais das linguagens constituídas de estruturas empíricas de acesso visualmente independente: na seqüência, o potencial comunicativo das mesmas será analisado.

Tátil-auditiva interdependente e tátil e auditiva independentes: Possuem grande potencial comunicativo na medida em que são capazes de veicular significados vinculados às representações não-visuais. Em outras palavras, utilizando-se de maquetes e de outros materiais possíveis de serem tocados e observados auditivamente, vinculam-se os significados às representações tátil e auditiva, e, por meio da estrutura mencionada, esses significados tornam-se acessíveis aos alunos cegos ou com baixa visão.

Fundamental auditiva e auditiva e visual independentes: essas estruturas empíricas possuem um potencial comunicacional atrelado ao detalhamento das informações veiculadas. Isso implica dizer que a qualidade da acessibilidade do aluno cego ou com baixa visão dependerá da intensidade descritiva oral dos significados que se pretendem comunicar. Descrição oral detalhada de gráficos, de tabelas, comportamento geométrico de raios e de fenômenos luminosos, passagens matemáticas, são exemplos do potencial comunicacional dessas estruturas empíricas. Nesse contexto, a utilização de recursos instrucionais visuais como lousa, data-show, retroprojetor, não são necessariamente inconvenientes (SOLER, 1999). Tais recursos podem ser utilizados em salas de aulas que contenham alunos com deficiência visual, desde que o elemento "descrição oral detalhada" seja explorado ao máximo. É importante ressaltar que, na hipótese de a descrição oral tornar-se insuficiente, a introdução de registros e esquemas táteis será sempre adequada e necessária para a veiculação de informações.

5) A realização de atividades comuns aos alunos com e sem deficiência visual: Uma dificuldade que esteve presente junto à utilização de linguagem tátil-auditiva interdependente, foi a ocorrência de atividades particulares para os alunos com deficiência visual. Essas atividades foram realizadas simultaneamente à aula ministrada para todos os alunos e visaram suprir dificuldades oriundas dessas aulas. Em linhas gerais, um dos licenciandos ministrava a aula, enquanto outros apresentavam explicações aos alunos (A) e (B). Na maioria das vezes, essas explicações foram realizadas com o auxílio de maquetes táteis construídas previamente. Assim, embora a ocorrência das atividades particulares tenha tido como justificativa o atendimento adequado de necessidades educacionais, entende-se, pelos motivos na seqüência explicitados, queas mesmas representaram dificuldadedeâmbito metodológi co para a inclusão dos alunos com deficiência visual.

I) Como, durante a realização das atividades particulares, a aula ministrada para todos os alunos não previa a realização de atendimentos individualizados, tais atividades representaram uma diferenciação excludente. 
Em tais ambientes, os diálogos entre licenciando e al unos cegos ocorriam em voz baixa, fato que explicita sua característica de incômodo à aula principal. Não se pode negar que as atividades particulares representaram uma das alternativas encontradas pelos licenciandos para o acesso dos al unos com deficiência visual aos conteúdos de óptica. Todavia, a realização de tais atividades evidencia as dificuldades enfrentadas por esses alunos na aula ministrada, que deveria, na hipótese de ser inclusiva, fornecer as condições à participação efetiva de todos.

II) Nas atividades particulares, temas discutidos, durante a aula, ou não foram abordados ou foram substituídos, diferenciando-se, portanto, daqueles trabalhados com os alunos videntes. Também eram enfocados temas abordados anteriormentenas aulas. Dessa forma, por vezes, assuntos interessantes aos al unos com deficiência visual não podiam ser por eles acompanhados no momento em que eram apresentados.

Portanto, as atividades particulares constituíram ambientes separados de ensino e representam uma dificuldade metodológica a ser superada. A tendimentos particularizados observados em aulas que previam tal prática junto a todos os al unos não foram considerados atividades particulares. Isso implica dizer que a posição adotada não é contrária à realização de atendimentos particularizados para quaisquer alunos, esim, àquel es querepresentam ambientes separados de ensino.

6) A bordagem dos múltiplos significados de um fenômeno óptico: em particular, essa alternativa é fundamental ao contexto dos fenômenos de significados indissociáveis de representações visuais e dos alunos cegos de nascimento. Se o aluno é cego de nascimento, é preciso reconhecer que significados indissociáveis de representações visuais não Ihes podem ser comunicados. Por outro lado, todo fenômeno óptico é constituído de múltiplos significados. N essesentido, énecessário enfocar o máximo designificados possíveis ligados ao fenômeno estudado (significados vinculados às representações nãovisuais, significados indissociáveis de representações não-visuais, a aspectos sociais, históricos, tecnológicos, etc).

7) Envolver os alunos com e sem deficiência visual em atividades interativas e dialógicas: a presente recomendação representa alternativa à dificuldade metodológica exposta no item 5. As atividades devem ser organizadas prioritariamente em função de contextos comunicacionais que favoreçam a interatividade entre seus participantes. A interatividade aproxima o aluno com deficiência visual de seus colegas videntes e do professor, e tal aproximação faz com que esses participantes busquem formas adequadas de comunicação. 


\section{CONSIDERAÇões FINAIS}

A veiculação dos significados vinculados e indissociáveis de representações não-visuais constituiu-se como a base fundamentadora das viabilidades de comunicação entre os licenciandos e o aluno (B). Tal veiculação objetivou-se por meio delinguagens constituídas de estruturas empíricas deacesso visualmente independente (fundamental auditiva, auditiva e visual independentes, tátil e auditiva independentes e tátil-auditiva interdependente). Para o aluno (A), as viabilidades comunicacionais estiveram atreladas aos significados vinculados às representações não-visuais, bem como, aos indissociáveis derepresentações visuais. Esses significados foram veiculados pelas estruturas tátil-auditiva interdependente e fundamental auditiva.

Verificou-sequeo emprego delinguagens deacesso tátil e/ ou auditivo é fundamental à criação de canais comunicacionais entre vidente e deficiente visual. Dentre tais linguagens, destaca-se a de estrutura empírica tátil-auditiva interdependente, que vincula determinados significados ópticos (vinculados a representações visuais) às representações táteis. Linguagens constituídas da mencionada estrutura empírica foram responsáveis por $60,82 \%$ das viabilidades comunicacionais do aluno (B) e 76,74\% das do aluno (A).

Observou-se, de forma discreta para o aluno (B), o enfoque de significados indissociáveis de representações não-visuais (absorção da luz e relação entre energia luminosa e térmica). Esse tipo de significado não foi relacionado a viabilidades do al uno $(A)$, pois, no dia de seu enfoque, o mencionado aluno não esteve presente. A abordagem desses significados é importante, na medida em que contribui para a compreensão da multiplicidade conceitual que envolve a óptica. Isso favorece a construção de significados ópticos por alunos cegos de nascimento, os quais não têm acesso aos significados indissociáveis de representações visuais. Favorece também a construção de significados ópticos por alunos que perderam a visão ao longo da vida, dos que possuem baixa visão, como também dos alunos videntes.

Nesse sentido, éconveniente mencionar quea óptica, enquanto campo de conhecimento, participa de um contexto mais amplo, ou seja, o da ondulatória, e representa, nesse contexto, uma pequena faixa do espectro el etromagnético. A luz enfocada, nessa perspectiva, não depende de significados indissociáveis de representações visuais, e sim do entendimento de comportamentos geométricos tridimensionais de campos elétricos e magnéticos não visíveis diretamente. Enquanto objeto de ensino e compreensão, tais comportamentos são tornados visíveis por meio designificados vinculados às representações visuais, originando, dessa forma, boa partedas dificuldades comunicacionais entre videnteedeficiente visual. A reflexão exposta também aplica-se à compreensão da luz enquanto constituída por fótons. Tais partículas, por não serem observadas visualmente, também são desprovidas de significad os indissociáveis de representações visuais. Ocorre que, para tornarem-se mentalmente representáveis, compreensíveis, 
muitos dos significados ópticos são visualmente registrados ou esquematizados. Essa ação é transportada à esfera educacional, de tal forma que os registros e esquemas visuais atuam como a base conceitual desses significados. Em geral, uma pessoa se convence que conhece um determinado fenômeno óptico quando constrói representações mentais visuais desse fenômeno. Esse fato, como indica Masini (1994), denota a influência da "cultura de videntes", no âmbito educacional, e reflete a crença na objetividade da visão. As linguagens, aqui apresentadas, mostraram um caminho à superação de dificuldades como as mencionadas.

Finalizando, a criação de canais comunicacionais adequados tem o potencial de incluir alunos com deficiência visual junto a processos intrínsecos de ensino/ aprendizagem tais como a criação de hipóteses, a elaboração de dúvidas, reformulação e construção de conhecimentos, etc. Sem a utilização de canais comunicacionais adequados, alunos com deficiência visual encontrar-seão, do ponto de vista conceitual e procedimental, numa condição de exclusão no interior da sala de aula. A comunicação representa, portanto, a variável central para a ocorrência de inclusão escolar de al unos com deficiência visual. A partir da construção de um ambiente comunicacional adequado, esses alunos terão condições estruturais básicas de participação efetiva junto aos processos deensino/ aprendizagem de óptica.

\section{Referências}

BAJO, M.; CAÑAS, J. Las imágenes mentales. In: RUIZ VARGAS, J. (Org.) P sicología de la memoria. Madrid: Alianza Editorial, 1991. p. 267-288.

BARDIN, L. A nálise de Conteúdo. Lisboa: Edições 70, 1977.

BRASIL. Decreto n. 3.298, de 20 de dezembro de 1999. 2004. Disponível em: ‘http:/ / www.cedipod.org.br $>$.

Brasil, MEC. Parâmetros Curriculares Nacionais: Adaptações Curriculares, 1998. In: < www.educacaoonline.pro.br/ adaptacoes_curriculares.asp > A cesso em 10/ 05/ 2005.

CAMARGO, E. P.; NARDI, R. Ensino de conceitos físicos de termologia para alunos com deficiência visual: dificuldades e alternativas encontradas por licenciandos para 0 planejamento de atividades. Revista Brasileira deE ducação Especial, Marília, v.12, n. 2, p.149168, 2006.

CAMARGO, E.P. A formação de professores de física no contexto das necessidades educacionais especiais de alunos com deficiência visual: o planejamento de atividades de ensino de física. 2006. 120f. Relatório final (pós-doutorado em Educação Para a Ciências) - Programa de Educação para a Ciência, Á rea deConcentração: Ensino deCiências - FaculdadedeCiências, Universidade Estadual Paulista "Júlio de Mesquita Filho", Bauru, 2006 
CAMARGO, E.P. A . 0 ensino deFísica no contexto da deficiência visual: elaboração econdução de atividades de ensino de Física para alunos cegos e com baixa visão. 2005. 272f. Tese (Doutorado em Educação) - Faculdade de Educação, UniversidadeEstadual de Campinas, Campinas, 2005.

U m estudo das concepções alternativas sobre repouso e movimento de pessoas cegas. 2000. 218f. D issertação (M estrado em edu cação para a ciência)- Programa deEducação para a Ciência, Área de Concentração: Ensino de Ciências - Faculdade de Ciências, Universidade Estadual Paulista “Júlio de Mesquita Filho”, Bauru, 2000.

CARVALHO, A. M. P.; GIL-PEREZ, D. Formação de professores de ciências. São Paulo: Cortez, 1994.

COMPIANI, M. A dinâmica discursiva nas salas de aula de ciências. In: ENCONTRO INTERNACIONAL LINGUAGEM, CULTURA E COGNIÇÃO: REFLEXÕES PARA O ENSINO, 2, Belo Horizonte, 2003. A nais... Belo Horizonte, 2003. 1 CD-ROM.

Dimblery, R.; BURTON, G. M ais do quePalavras: uma introdução à teoria da comunicação. 4. ed. São Paulo: Cortez, 1990.

EISENCK, M.; KEANE, M. Cognitive Psychology: a student's handbook. London: Erlbaum, 1991.

FRA NÇA , V. V. O objeto da comunicação: a comunicação como objeto. In: HOH LFELDT, A.; MARTINO, L. C.; FRA NÇA, V.V. (Org.). Teoria da comunicação: conceitos, escolas etendências. 5. ed. Petrópolis: Vozes, 2005. p. 39-60.

MANTOAN, M. T. E. Inclusão Escolar: O queé? Por quê? Como fazer? São Paulo: M oderna, 2003.

MARTINO, L.C. Dequal comunicação estamos falando? In: HOH LFELDT, A.; MARTINO, L. C.; FRAN ÇA, V. V. (Org.). Teoria da comunicação: conceitos, escolas e tendências. 5. ed. Petrópolis: Vozes, 2005. p. 11-25.

MASINI, E. F. S. Impasses sobre o conhecer e o ver. in: 0 perceber eo relacionar-se do deficiente visual: orientando professores especial izados. Brasília: CORDE, 1994.

MEGID NETO, J. Sobreas pesquisas em ensino deFísica nós podemos saber, mas como social izar esses conhecimentos? In: EN CONTRO DE PESQUISA EM ENSINO DE FÍSICA, 7, 2000, Florianópolis. A nais eletrônicos... (CDR). Florianópolis: UFSC, 2000.

MITTLER, P. Educação inclusiva: contextos sociais. São Paulo: ARTMED, 2003.

MORTIMER, E. F. A presentação do VI ENPEC. in: MORTIMER, E. F. (Org.). EN CONTRO NACIONAL DE PESQUISA EM EDUCA ÇÃ O EM CIÊNCIAS, 6, Florianópolis. Caderno de resumos... ABRAPEC, 2007. CD-ROM. p. 9-11,

MORTIMER, E. F.; SCOTT, P. H. A tividade discursiva nas salas de aula de ciências: uma ferramenta sociocultural para analisar eplanejar o ensino. Investigações em En sino deCiências, Porto Alegre, v.7, n.3, 2002.

NARDI, R. Pesquisas em ensino defísica. 2. ed. São Paulo: Escrituras, 2001. 
CAMARGO,E.P.; NARDI, R

RODRIGUES, A. J. Contextos de aprendizagem e integração/ inclusão de al unos com necessi dades educativas especiais. In: RIBEIRO, M.L.S.; BAUMEL, R.C.R. (Org.). Educação Especial - Do querer ao fazer. São Paulo: A vercamp, 2003. p. 13-26.

SASSA KI, R. K. Inclusão: construind o uma sociedadepara todos. 5. ed. Rio deJaneiro: WVA editora, 1999.

SOLER, M. A. D idáctica multisensorial delas ciencias. Barcelona: Ediciones Paidós I bérica S.A, 1999.

VIGOTSKI, L. S. Fundamentos de defectologia: El niño ciego. In: Problemas especiales da defectologia. Havana: Editorial Pueblo Y Educación, 1997. p. 74-87.

ZABA LA , A. A prática edu cativa: como ensinar. Porto A legre: Artmed, 1998.

Recebido em 18/ 02/ 2008

Reformulado em 02/ 06/ 2008

Aprovado em 04/ 12/ 2008 